\section{Sulphydryl Reagents and Rh Activity of Erythrocyte Stroma}

IT has recently been shown that the $\mathrm{Rh}$ activity of lyophilized human Rh-positive stroma could be abolished with certain sulphydryl reagents, that this could be prevented by the concurrent addition of excess thiol, and that the loss was reversible with one such reagenti. It was not ostablished whether the antigenic activity of non-lyophilized erythrocytes shows such an effect. The resolution of this problem was hampered in the case of intact cells by the presence of soluble sulphydryl systems, including haemoglobin and glutathione ${ }^{2}$, and in the case of non-lyophilized stroma both by the occlusion of these soluble components, and by the difficulty of quantitation of wet stroma. The results of the present experiments suggest that the loss of Rh activity of lyophilized stroma brought about by sulphydryl reagents is equally true of stroma which has not been lyophilized.

'Two methods of obviating occlusion were used. The first may be termed a $p \mathrm{H}$ shuttle, and consisted of washing the intact cells in 0.9 per cent sodium chloride, rupturing in distilled water, adjusting the $p \mathrm{H}$ under continuous monitoring to 8.3 with trisodium phosphate, then adding citric acid to $p H 5 \cdot 5$, followed by centrifugation. The residue was then taken up in 15-20 times its volume of distilled water and the process repeated. At the higher $p \mathrm{H}$ the suspended phase assumed approximately colloidal dimensions and occluded material was released. Five or six such shuttlo steps were required and it was noted that some loss of $R$ h activity resulted. A second method was then used which did not appear to result in loss of activity. Rapid freezing at the temperature of solid carbon dioxide was substituted for the $p \mathrm{H}$ shuttle, and the material was washed with distilled water. The freezethaw procedure was repeated twice.

Using stroma washed with the freeze-thaw method a fine uniform suspension was made up volumetrically in distilled water, a measured portion removed, lyophilized and weighed, and the relation between dry weight and volume calculated. 'T'wenty mg of the lyophilized suspension was matched with the corresponding volume of nonlyophilized stroma. The samples wore washed with $0 \cdot 1 \mathrm{M}$ sodium phosphate buffer $(p \mathrm{H} 7 \cdot 0)$, centrifuged and treated with $10^{-4}$ M. $p$-chloromercuribenzoate (Nutritional Biochemicals) in the same buffer for $60 \mathrm{~min}$ at $22^{\circ} \mathrm{C}$ with agitation. A similar set was treated with phosphate buffer only. The experiment was repeated using $3 \times 10^{-4} \mathrm{M}$ reagent. The specimens were then contrifuged, washed twice with phosphate buffer, and 1 or $2 \mathrm{ml}$. human isoimmune anti-D suitably diluted in normal human serum were added. The dilution was standardized so that $20 \mathrm{mg}$ of untreated O Rh positive lyophilized stroma could just remove all anti-D activity after 60 min incubation at $37^{\circ} \mathrm{C}$, and subsequent centrifugation. Similarly for the present experiments the supernatants after centrifugation were studied for residual anti-D activity against trypsinized $O$ positive erythrocytes, as previously described ${ }^{1}$. The results are summarized in Table 1. The partial loss of activity with the lower coneentration of $p$-chloromercuribenzoate and the complete loss with the higher concentration were indistinguishable for lyophilized and non-lyophilized stroma. In each case no loss in activity was noted when 0.1 M 2-mercaptoethanol (Eastman Organic) was present with the sulphydryl reagent. The results of similar experiments with $N$-ethylmaleimide (Nutritional Biochemicals) are shown in Table 2.

Lyophilization of washed erythrocyte stroma results in the solubilization in 0.9 per eent sodium chloride of onethird its weight, consisting mostly of hexose-containing material of large molecular size together with some peptides $^{3}$. Since this probably indicates significant disruption of the coll wall the question arose whether the sensitivity of the $R h(D)$ antigen to sulphydryl reagents in the case of lyophilized cells might not be dependent
Table 1. RH ACtivity AND $p$-Chloromfrcuribenzodte

\begin{tabular}{|c|c|c|}
\hline O positive stroma & Treated with $5 \mathrm{ml}$. & $\begin{array}{l}\text { Resulting loss? } \\
\text { of Rh activity }\end{array}$ \\
\hline Non-lyophilized & Phosphate buffer, $p \mathrm{H} 7$ & None \\
\hline Non-lyophilized & $10^{-4}$ M PCMB in phosphate & Partial \\
\hline Non-lyophilized & $3 \times 10^{-6} \mathrm{M} \quad \mathrm{PCMB}$ in phosphate & Complete \\
\hline Non-lyophilized & $\begin{array}{l}3 \times 10^{-4} \mathrm{M} \text { PCMB and } 0.1 \mathrm{M} 2-\mathrm{ME}^{*} \\
\text { in phosphate }\end{array}$ & None \\
\hline $\begin{array}{l}\text { Lyophilized } \\
\text { Lyophilized }\end{array}$ & Phosphate buffer & None \\
\hline $\begin{array}{l}\text { Lyophinzed } \\
\text { Lyophilized }\end{array}$ & $10^{-6}$ M PCMB in phosphate & Partial \\
\hline Iyophilized & $3 \times 10^{-4} \mathrm{M}$ PCMB and $0.1 \mathrm{M} 2$-ME & None \\
\hline
\end{tabular}

Twenty-mg specimens were all from the same donor, and were incubated at $22^{\circ} \mathrm{C}$ for $60 \mathrm{~min}$ with agitation. After washing twice with phosphate, anti-D serum was added and incubated for $60 \mathrm{~min}$ at $37^{\circ} \mathrm{C}$. After centrifugation, the supernatant was studied for residual anti-D activity.

2-mercaptoethanol.

Table 2. $\mathrm{R}_{\mathrm{H}}$ Activity AND $N$-ETHYLMaleimide

\begin{tabular}{|c|c|c|}
\hline $\mathrm{O}$ positive stroma & Treated with $5 \mathrm{ml}$. & $\begin{array}{l}\text { Resuiting loss } \\
\text { of Rh activity }\end{array}$ \\
\hline Non-lyophilized & Phosphate buffer & None \\
\hline Non-lyophilized & $10^{-3} \mathrm{M}$ NEM in phosphate (at $22^{\circ}$ ) & Partial \\
\hline Non-iyophilized & $10^{-3} \mathrm{M}$ NEM in phosphate (at $37^{\circ}$ ) & Complete \\
\hline Non-lyophilized & $\begin{array}{l}10^{-3} \mathrm{M} \text { NEM and } 0 \cdot 1 \mathrm{M} 2-\mathrm{ME} \text { in } \\
\left.\text { phosphate (at } 37^{\circ}\right)\end{array}$ & None \\
\hline $\begin{array}{l}\text { Lyophilized } \\
\text { Jyophilized }\end{array}$ & $\begin{array}{l}\text { Phosphate buffer } \\
10^{3} \mathrm{M} \text { NEM in whosphate (at } 22^{\circ} \text { ) }\end{array}$ & $\begin{array}{l}\text { None } \\
\text { Partial }\end{array}$ \\
\hline Lyophilized & $10^{-3} \mathrm{M}$ NEM in phosphate (at $37^{\circ}$ ) & Complete \\
\hline Lyophilized & $\begin{array}{l}10^{-3} \mathrm{M} \text { NEM and } 0 \cdot 1 \mathrm{M} 2-\mathrm{ML} \text { in } \\
\text { phosphate (at } 37^{\circ} \text { ) }\end{array}$ & None \\
\hline
\end{tabular}

on the lyophilization process itself. These results show that such sensitivity does not depend on lyophilization. Freezing of intact erythrocytes without drying is not associated with significant disruption under certain circumstances ${ }^{4}$ and it would not be anticipated that freezing and thawing of stroma would result in changes comparable to lyophilization. The present investigation does not show whether the $\mathrm{Rh}$ antigen of the intact crythrocyte is capable of reacting with sulphydryl reagents.

This investigation was supported by grants from the National Institute of Arthritis and Metabolic Diseases, National Institutes of Health and the National Foundation.

I thank Gary L. Rodney for technical assistance.

Department of Medicine, Floyd A. Green

State University of New York at Buffalo, and Buffalo General Hospital,

Buffalo, New York.

${ }^{1}$ Green, F. A., Vox Sang., 10, 32 (1965).

${ }^{2}$ Kasbekar, D. K., and Srcenivasan, A., Biochem. J., 72, 389 (1959).

${ }^{3}$ Green, F. A. (unpublished observations).

${ }^{4}$ Mollison, P. L., and Sloviter, H. A., Lancet, ii, 862 (1951).

\section{Copper Transport in Mammalian Tissues}

ReCentwy, Neumann and Silverberg ${ }^{1}$ presented results of experiments which were very similar to those which we had briefly reported earlier ${ }^{2,3}$. They concluded that amino-acids facilitate the transport of copper at the cellular level and presented conclusive evidence to support this. They further concluded that the facilitation of copper transport by amino-acids fulfils the criteria of an "active transport system", as it is dependent on temperature, concentration and oxygen, and operates against a chemical concentration gradicnt.

We believe that the latter conclusion cannot be based on the evidence presented by Neumann and Silverberg. Their first two critcria, dependence on temperature and on concentration, apply equally to the processes of simple or facilitated diffusion. Dependence on oxygen may indicate a dependence on chemical energy - but this is not necessarily so. The last criterion-the operation of the copper transport against a chemical concentration gradient-cannot be used as an argument in favour of this being an "active transport" as the concentrations of free copper ions on either side of the membrane are not known. In fact, it is well known that most of the copper in both the extracellular and the intracellular compartments is bound to various ligands. Therefore, concentration of the label in the slices, the development of a ratio 